\title{
Entrepreneurship Education and Training in a Small Business Context: Insights from the Competence-based Approach
}

\author{
Thomas Lans, Wim Hulsink, Herman Baert and Martin Mulder
}

\begin{tabular}{|l|l|}
\hline \multicolumn{2}{|l|}{ ERIM REPORT SERIES RESEARCH IN MANAGEMENT } \\
\hline ERIM Report Series reference number & ERS-2008-028-ORG \\
\hline Publication & May 2008 \\
\hline Number of pages & 22 \\
\hline Persistent paper URL & http://hdl.handle.net/1765/12466 \\
\hline Email address corresponding author & whulsink@rsm.nl \\
\hline Address & Erasmus Research Institute of Management (ERIM) \\
& RSM Erasmus University / Erasmus School of Economics \\
& Erasmus Universiteit Rotterdam \\
& P.O.Box 1738 \\
& 3000 DR Rotterdam, The Netherlands \\
& Phone: + 31104081182 \\
& Fax: $\quad+31104089640$ \\
& Email: info@erim.eur.nl \\
& Internet: $\quad$ www.erim.eur.nl \\
\hline
\end{tabular}

Bibliographic data and classifications of all the ERIM reports are also available on the ERIM website: www.erim.eur.nl 


\section{ERASMUS RESEARCH INSTITUTE OF MANAGEMENT}

\section{REPORT SERIES \\ RESEARCH IN MANAGEMENT}

\begin{tabular}{|l|l|}
\hline ABSTRACT AND KEYWORDS \\
\hline Abstract & $\begin{array}{l}\text { The concept of competence, as it is brought into play in current research, is a potentially } \\
\text { powerful construct for entrepreneurship education research and practice. Although the concept } \\
\text { has been the subject of strong debate in educational research in general, critical analysis of how } \\
\text { it has been used, applied and experienced in entrepreneurship education practice is scarce. This } \\
\text { article contributes specifically to the discussion of entrepreneurial competence by theoretically } \\
\text { unfolding and discussing the concept. Subsequently, the implications of applying a competence- } \\
\text { based approach in entrepreneurship education are illustrated and discussed based on analysis } \\
\text { of two cases that were aimed at identifying, diagnosing and eventually developing } \\
\text { entrepreneurial competence in small businesses in the Netherlands and Flanders (Belgium). The } \\
\text { cases show that the added value of focussing on competence in entrepreneurship education lies } \\
\text { in making the (potential) Small business owner aware of the importance of certain } \\
\text { entrepreneurial competencies and in providing direction for competence development. In this } \\
\text { process it is fundamental that competence is treated as an item for discussion and interpretation, } \\
\text { rather than as a fixed template of boxes to be ticked. Furthermore the cases highlight that a } \\
\text { competence-based approach does not determine the type of educational and instructional } \\
\text { strategies to be used. Its consequential power in that respect is limited. }\end{array}$ \\
\hline Entrepreneurship, education, competence-based training, small businesS, entrepreneurial \\
learning, competence
\end{tabular}




\title{
Entrepreneurship education and training in a small business context: insights from the competence-based approach
}

\author{
Thomas Lans \\ Wageningen University, the Netherlands \\ thomas.lans@wur.nl \\ Wim Hulsink \\ RSM Erasmus University \& Wageningen University, the Netherlands ${ }^{1}$ \\ whulsink@rsm.nl
}

Herman Baert

University of Leuven, Belgium

Herman.Baert@ped.kuleuven.be

Martin Mulder

Wageningen University, the Netherlands

martin.mulder@wur.nl

\section{Key words:}

Entrepreneurship, education, competence-based training, small business, entrepreneurial learning, competence

\begin{abstract}
The concept of competence, as it is brought into play in current research, is a potentially powerful construct for entrepreneurship education research and practice. Although the concept has been the subject of strong debate in educational research in general, critical analysis of how it has been used, applied and experienced in entrepreneurship education practice is scarce. This article contributes specifically to the discussion of entrepreneurial competence by theoretically unfolding and discussing the concept. Subsequently, the implications of applying a competence-based approach in entrepreneurship education are illustrated and discussed based on analysis of two cases that were aimed at identifying, diagnosing and eventually developing entrepreneurial competence in small

\footnotetext{
${ }^{1}$ Please send correspondence to: Willem Hulsink, eShip Erasmus Centre of Entrepreneurship, Rotterdam School of Management, Erasmus University, PO Box 173, 3000 DR Rotterdam, the Netherlands. Email: Whulsink@rsm.nl.
} 
businesses in the Netherlands and Flanders (Belgium). The cases show that the added value of focussing on competence in entrepreneurship education lies in making the (potential) small business owner aware of the importance of certain entrepreneurial competencies and in providing direction for competence development. In this process it is fundamental that competence is treated as an item for discussion and interpretation, rather than as a fixed template of boxes to be ticked. Furthermore the cases highlight that a competence-based approach does not determine the type of educational and instructional strategies to be used. Its consequential power in that respect is limited.

\section{Introduction}

The interest in developing entrepreneurship is not something new; as early as the 1980s Stevenson and Gumpert opened their article on 'the heart of entrepreneurship' with the following observation "Suddenly entrepreneurship is in vogue. If only our nation's businesses - large and small - could become more entrepreneurial we would improve our productivity and compete more effectively in the world marketplaces" (Stevenson and Gumpert, 1985, p. 2). Despite the persistent myth that entrepreneurs are born and not made, there is a growing volume of research that acknowledges the importance of entrepreneurship education and training ${ }^{2}$ as a source for increasing start-up intentions, survival rates and growth (Katz, 2007). This importance is clearly reflected in the enormous (financial) efforts that are put into entrepreneurship and small business support programmes. This increased attention is directed not only towards realising more spin-offs or start-ups, and thereby stimulating nascent entrepreneurship, but also at improving entrepreneurship in itself, thus making business owners (as well as employees) more competent as entrepreneurs ${ }^{3}$. According to Fayolle and Klandt (2006), in contemporary entrepreneurship education, entrepreneurship can be viewed from three different angles, namely as a matter of culture or state of mind, as a matter of behaviour, or as a matter of creating specific situations. Education focussed on entrepreneurship as a matter of culture/state of mind encompasses those aspects that focus on values, beliefs and attitudes associated with entrepreneurship (i.e. entrepreneurial mindset, spirit or identity). Entrepreneurship education focussed on

\footnotetext{
${ }^{2}$ We take a broad definition of entrepreneurship education in line with Fayolle and Klandt (2006) and Katz (2007), thus defining it not solely as initial education focussing on the creation of new businesses but also as any programme or process aimed at the development of the profession of entrepreneurship (e.g. making business owners more competent).

${ }^{3}$ From an entrepreneurship research perspective it is important to carefully define terms such as self employed, small business owner, starters, nascent entrepreneurs, etc. However, since our focus was on entrepreneurship education in its broadest sense (see footnote above) these terms are used more freely in this article.
} 
behaviour deals mostly with specific skills in relation to entrepreneurial behaviour, like seizing opportunities, making decisions and social skills. Finally, entrepreneurship education focussed on creating specific situations, concerns the creation of new firms and entrepreneurial situations (e.g. new ventures, corporate venturing). Whereas the focus of entrepreneurship education in the past was on the last dimension (venture creation, e.g. writing business plans), many current scholars argue that the real challenge for entrepreneurship education lies within the development of the first two dimensions, i.e. learning for entrepreneurship, rather than learning about entrepreneurship (e.g. Gibb, 2002; Honig, 2004).

In our opinion the concept of competence could serve to connect and stimulate use of the first two angles described by Fayolle and Klandt (2006) in entrepreneurship education. One of the key merits of focussing on 'modern' interpretations of competence is that they stress the interrelatedness of knowledge, skills and attitudes (Fiet, 2001; Hayton and Kelley, 2006; Markman, 2007; Man, 2006) and acknowledge the importance of the work context (Sandberg, 2000). Being entrepreneurially competent does not only mean that you know how to write a business plan, but it also implies that you recognise and act on opportunities, that you take initiative and action, for instance to convince investors to invest money in your project, and relate to potential suppliers and buyers. It implies that you are actually able to identify and further exploit an opportunity to create a viable business within a specific context, including its management and evaluation in the long run. Moreover, entrepreneurial competencies are put into practice and further developed by learning through experience, for instance through reflection on critical incidents (Cope and Watts, 2000), experimentation or observation (Mulder et al., 2007). Competence, as it is brought into play in current higher and vocational education (Stoof et al., 2002; Delamare le Deist and Winterton, 2005; Wesselink et al., 2007), could also serve as a powerful theoretical construct for the development of learning environments and trajectories (e.g. courses, coaching programmes) that aim at learning for entrepreneurship.

Although the concept of competence from an educational point of view has been the subject of strong debate in educational research in general (e.g. Eraut, 1994), critical analysis of how the concept has been used, applied and experienced in entrepreneurship education practice is scarce. Therefore, in this paper we describe and discuss two distinct practical cases from the Netherlands and Flanders (Belgium) in which entrepreneurial competencies 
were used as a starting point for entrepreneurship training. Both cases serve to answer the following broad research questions:

1. How was the concept of competence operationalised?

2. What principles and methods were used to diagnose entrepreneurial competencies?

3. What were the experiences of participants with competence-based instruments for learning trajectories aimed at entrepreneurship?

The paper starts by theoretically unfolding the conceptual boundaries of entrepreneurial competence and subsequently describes and discusses the two cases. The paper ends with a discussion and recommendations for entrepreneurship education as a field of scientific enquiry.

\section{Entrepreneurial competence as an integrative construct}

Although several frameworks are being developed to combine current thinking on entrepreneurship and competencies (e.g. Sullivan, 2000; Markman and Baron, 2003; Collins et al., 2006; Fuller-Love, 2006; Hayton and Kelley, 2006; Man, 2006), the concept of competence still seems to be surrounded by confusion and ambiguity (Stoof et al., 2002; Mansfield, 2003). This is caused by the different components of competence (representing outcomes, capabilities, tasks or personal traits/characteristics), different levels of analysis (e.g. organisation versus individual) and the different cultural/historical contexts, especially in Europe The concept also crosses disciplines like psychology (e.g. McClelland, 1998), organisational behaviour (e.g. Defillippi and Arthur, 1994), and educational sciences (e.g. Biemans et al., 2004). Many publications, especially from educational sciences, therefore refer to competence as a 'fuzzy concept' (Van der Klink and Boon, 2003).

Competencies have been described as broad personal characteristics necessary for superior behaviour (e.g. Boyatzis, 1982), as standards for occupations derived through functional analysis of jobs in a variety of contexts, or as generic, overarching prerequisites (e.g. meta-competencies). Of all the endeavours to describe and formulate competence, two perspectives have probably been most influential, namely the behavioural approach to competence (worker oriented) and the functional approach to competence (work oriented) (Eraut, 1994; Sandberg, 2000; Cheetham and Chivers, 1996; Delamare Le Deist and Winterton, 2005; Bolden and Gosling, 2006). If we look at the competence concept in the 
context of specific behaviours, McClelland (1973) was probably the first to mention the importance of competencies extracted from Behavioural Event Interviews in general and specifically in the field of entrepreneurship (McClelland, 1987). McClelland's ideas are based on the American tradition of 'personal competency', which is theoretically grounded in personality psychology and mainly covered in the work of White, McLagan, Boyatzis, Spencer and Spencer (Rothwell and Lindholm, 1999). In this tradition, competency is "an underlying characteristic (i.e. motive, trait, skill, aspect of one's self-image, social role or a body of knowledge) which results in effective and or/superior performance in a job" (Boyatzis, 1982, p.21). Two of the strengths of this model are that it has high validity due to large-scale testing and that it uses a wide range of psychometric techniques. One of the most important criticisms of the personal competency approach is that the model assumes a common set of individual capabilities no matter what the nature of the situation or task requires; the model assumes there is a single type of 'good' practitioner (i.e. entrepreneur, manager) independent of the context. Furthermore, a very practical issue remains unsolved, namely whether these competencies are learned, innate or both (Eraut, 1994).

A second stream of thought on competence, which is less known in entrepreneurship research, can be traced back to the UK, where competencies were embraced by the national government for Vocational Education and Training (VET), leading to the National Vocational Qualifications (NVQs) framework. In this framework, competencies were viewed as job-specific outcomes and operationalised through 'functional-analysis', a topdown analysis of jobs leading to their classification into different levels based on key purposes, key roles, units of competence and elements of competence (Cheetham and Chivers, 1996). Subsequently, performance criteria were defined which form the basis of assessments, with range indicators provided for guidance (Delamare Le Deist and Winterton, 2005). A basic criticism of this approach is that a list of atomised, fragmented, work descriptions does not indicate whether the worker is indeed able to accomplish these activities efficiently in practice. Furthermore these models have been criticised for lacking scientific underpinning, undervaluing the role of knowledge and generating relatively ‘conservative’ models of competence (Cheetham and Chivers, 1996).

Recent literature recognises that models of competence are gradually shifting from one-dimensional (e.g. merely behavioural, or merely functional) to multi-dimensional or holistic typologies (Delamare Le Deist and Winterton, 2005; Cheetham and Chivers, 1996). Many authors agree that the use of competence is only of added value when competence is 
seen as more than only knowledge, only skills or only behaviour (Fiet, 2001; Biemans et al., 2004; Hayton and Kelley, 2006; Markman, 2007), i.e. when it is seen as the integration of different elements required for effective performance in an organisation, job or task situation (Baert et al., 2000; Mulder, 2001). According to proponents of these multi-dimensional models of professional competence, competence can be described as a combination of core components. These core components are not independent from each other but should be seen in an integrated way. Professional competence (e.g. entrepreneurial competence) therefore encompasses cognitive competence (work-related knowledge and understanding), functional competence (job-related skills, know-how) and behavioural competence ('know how to behave') (Delamare Le Deist and Winterton, 2005). Furthermore, these competencies should be learnable. The notion in entrepreneurship literature of viewing competence from a learning perspective is set forth by Bird (1995) in her conceptual model of entrepreneurial competency. Bird (1995) rightly notices that there is no use in developing a model for entrepreneurial competence without considering the fact that these competencies should be learnable. The term 'learned entrepreneurial competence' is used to refer to competence that is not acquired at birth, but through education, training or experience. Limiting the concept of entrepreneurial competence to 'learned entrepreneurial competence' is defensible for several reasons. To start with, only a small proportion of individual differences in entrepreneurship (measured for instance in new venture performance) are captured by relatively stable and general psychological dispositional constructs such as need for achievement, locus of control and risk-taking propensity. Rauch and Frese (2007) make a distinction between broad personality traits of entrepreneurs (the 'big-five' taxonomy: extraversion, emotional stability, openness to experience, agreeableness and conscientiousness) and specific personality traits of entrepreneurs (e.g. need for achievement, risk taking, locus of control). In their study, need for achievement performed the best, but still only accounted for $7 \%$ of the variation in new venture performance (Baum and Locke, 2004). Competence-related motivational attitudes like self-efficacy (Bandura, 1982) and self-confidence (Fletcher and Bailey, 2003) seem to be constructs in this respect that should not be included in learned entrepreneurial competence, albeit for a different reason. Empirical findings in entrepreneurship literature have shown reciprocal effects between these constructs and the development of entrepreneurial competence (Maurer et al., 2003; Delmar and Goujet, 2006). Rather than being a component of competence, they should be taken as an important condition for specifying the relation between competence and 
performance. The same line of reasoning can be applied to cognitive constructs like intellectual abilities: the more general these abilities are the less they will contribute to the specific context of entrepreneurship and the more they will be a prerequisite for the development of entrepreneurial competence, rather than being an element of it. Therefore, a more specific conceptualisation of cognitive ability should be used, in order to include it as an element of entrepreneurial competence. For instance the ability to think differently, to use certain heuristics, to apply systematic search (entrepreneurial 'alertness'), and to recognise opportunities are assumed to be learnable (e.g. Baron and Ensly, 2006), and thus could be elements of competence.

\section{Entrepreneurial competence as an interpretive construct}

The perception of competence as an integrated learnable construct also reflects the way competence is identified and addressed in research and practice. As described in the previous section, the two main streams of thought on competence follow the worker-oriented approach (base on the work of McClelland and others) and the work-orientated approach (based on functional analysis of jobs). What these two dominant approaches have in common is that they create rather abstract, atomised descriptions of competence, ignoring the complexity of work contexts (Eraut, 1994; Sandberg, 2000). According to Bolden and Gosling (2006) competence profiles derived in this way can be seen as 'sheet music', indicating the notes, dynamics, phrases and melody of professional competence. However, in the end it is the arrangement, playing, venue, performers, acoustics, improvisations and influence of previous performances that bring sheet music to life. For instance, an important entrepreneurial competence like 'networking' can be quite different in different contexts, depending on values, culture, traditions, history, etc. Likewise, the way 'search for autonomy' is understood and put into practice in an individualistic, western culture may differ considerably from how it is understood and put into practice in a Chinese, collectivist and authority-oriented culture, for example. Moreover, some of the entrepreneur's competencies might be tacit or implicit and therefore easily overlooked by just focussing on the 'sheets' of the music. These issues comprise probably the most fundamental problem with the competence approaches derived in this fashion. Boreham (2006) summarises these approaches to competence as 'bolt-on' approaches, illustrating the rationalistic view of competence as something that can be 'added' (learned) without considering the larger context. 
Recent approaches that take a radically different position concerning competence and its underlying assumptions can be referred to as co-constructive (Boreham, 2006) or interpretive models of competence (Sandberg, 2000). In this view, the enactment and development of competencies are socially constructed and context dependent. Applying the interactionist dictum that people and their world(s) are inextricably related through their lived experiences, this approach argues that workers and their work clot together while carrying out their activities, experiencing it and making sense of them. Unlike the 'bolt-on' perspective, which assumes strong, static situations and narrowly defines individual attributes and task descriptions, this co-construction approach starts from relatively open and weak, pliable situations in which workers shape their labour activities, and their behaviour is in its turn structured by the rules and procedures of their work (Markman, 2007). Such a context dependent and interpretive approach to competencies can be a valuable addition to the established literature on the traits, motivations and behaviours of entrepreneurs, for instance by further specifying the relevance of skills, abilities, and cognitions, and their evolution over time. For instance, in a setting with no pre-defined rules and procedures and major uncertainty about the role(s) of a new firm's founder/owner, the inventor-entrepreneur may rely upon insight, discovery and opportunity recognition; whereas at a later stage in the firm's development, exploitation and appropriation are clearly more important for the entrepreneur-manager.

On the basis of the relevant literature, table 1 provides an overview of the differences between what we label as a 'bolt on' model of entrepreneurial competence (emphasising the fixed, objective, template thinking) and an interpretive/integrative model of entrepreneurial competence.

Table 1 Two types of approaches to entrepreneurial competencies

\begin{tabular}{|l|l|}
\hline $\begin{array}{l}\text { Radical ‘bolt on’ model of entrepreneurial } \\
\text { competence }\end{array}$ & $\begin{array}{l}\text { Radical 'interpretive/integrative’ model of } \\
\text { entrepreneurial competence }\end{array}$ \\
\hline Objective & Socially constructed \\
\hline Context independent & Context dependent \\
\hline Atomistic & Integrated \\
\hline Attributes are point of departure & Conceptions are point of departure \\
\hline Closed & Open \\
\hline
\end{tabular}




\section{Questions and challenges for entrepreneurship education and training}

From the above review of relevant literature it can be concluded that modern conceptualisations of competence are not limited to behavioural elements of competence ('know how to behave'), but include cognitive (understanding) as well as functional elements (skills, or know-how). Furthermore, entrepreneurial competence should be viewed as learned (rather than instinctual) and as a construct that requires interpretation and understanding. This view of entrepreneurial competence has important consequences for educational practices, especially with respect to the identification and diagnoses of competencies as starting points for education and training (Sandberg, 2000). For instance, the identification of crucial entrepreneurial competencies requires a dialogue between the teacher, educator or facilitator and the (future) entrepreneur (Wesselink et al., 2007). Together they have to actively construct the meaning of competence in the participants' particular line of work. Furthermore an integrative, interpretive approach to competence also emphasises a direct relationship between work and worker, or in this situation between (future) entrepreneur and (future) work/business environment. For practices aimed at competence development, this could for instance imply learning from authentic and complex situations, like challenges or problems faced in the context of work, rather than learning from situations that focus simply on 'filling' knowledge gaps. However, the implications and usefulness of adopting a competence-based approach are not clearly presented in current entrepreneurship education literature.

\section{Methods}

To research the implications and usefulness of adopting a competence-based approach to entrepreneurship education, a case study methodology was utilised to explore how entrepreneurial competencies have been identified, diagnosed and experienced in practice. As there is not much existing literature in the field of entrepreneurship on how competencies are used, applied and experienced in entrepreneurship education, this case study could be labelled as explorative. Since case studies allow for detailed, context-rich descriptions, the cases were also used to illustrate principles and methods to introduce a competence-based approach and to highlight the approach's strengths and weaknesses. The two cases, from the Netherlands and Flanders (Belgium), were selected on the basis of the authors' involvement in the two projects. In both cases the primary reason for introducing a competence-based framework was the assumption that (potential) entrepreneurship in a small business context 
can be enhanced by learning entrepreneurial competencies. Case selection on the basis of the authors' involvement can be regarded as a strength (added insight), but at the same time as a weakness, since it might bias the results. Therefore, multiple sources of evidence as well as key informants were utilised to collect data, thereby improving the construct validity of the cases. Data were collected in 2005/2007 by means of written documentation on both training programmes (in particular formative and summative evaluations), group interviews among the facilitators, and surveys among the participants. In the following section a more detailed description of both cases is given.

Case: PlattelandImpuls (RI), the Netherlands.

The PlattelandImpuls ('Rural Impulse') (RI) project was carried out by Vrienden van het Platteland ('Friends of the Rural area'), LTO-Nederland (Dutch Farmers' Association), Wageningen University and Research Centre (Wageningen UR) and cooperation Stadteland ('city-on-the-countryside') to stimulate owners of 'pluriactive' farms to develop entrepreneurial competencies and work out new product-market combinations. Multiple businesses ownership in farming, or pluriactivity as it is known, has always been an important and distinctive feature of farming (Carter, 2001). The number of farms with new activities is increasing, both in the Netherlands and abroad.

The RI project included a training course focused on enhancing and professionalizing entrepreneurship in several types of pluriactivity, like nature conservation, care, education, tourism. The training was a group activity, meaning that groups were formed of business owners that had similar business plans for the near future. The sessions were geared towards helping the farmers focus their ambitions, develop action plans, achieve a better understanding of and develop their (future) product, their (future) market and their personal entrepreneurship. Approximately 350 small farm holders participated in the RI training course, which began with an intake meeting. After this intake groups were selected for a self assessment by means of an e-questionnaire about entrepreneurial competence. All groups had 6 meetings. The first session was a group discussion on the results of the intake. The following (2-5) training sessions were primarily aimed at working out a concrete plan for the farmers' business ideas (or as they called it, a 'breakthrough' agenda). The groups were facilitated by experts from consultancy companies, applied scientists and role models from the sector. In the last meeting, the results of the project were harvested and the ambitions for 
the future were identified and discussed within the group. Furthermore, the participants, as well as the facilitators, were evaluated on the basis of a questionnaire and a group discussion about the use of the concept of competence in the intake and the training course (Schoorlemmer and de Wolf, 2008).

Case: ENTRE project, Flanders, Belgium

The ENTRE project in the Flemish Region of Belgium was initiated by Syntra Flanders (Flemish institute for training and education of the self-employed) to introduce new learning trajectories that foster self-employment and entrepreneurship. It was initiated as a response to the growing importance of entrepreneurial activity and competence-based education in Europe and Flanders and in particular to gain better understanding of entrepreneurial competence and its application in assessment, training and coaching. The specific objectives of the ENTRE project were to design a competence profile for successful entrepreneurs in the small- and medium-sized enterprise (SME) context; to develop, design and implement an intake interview focussed on entrepreneurial competence, to develop competence-based educational programmes for (candidate) entrepreneurs and to further develop educational programmes for coaches, facilitators and assessors. The point of departure of the project's training programmes was the ENTRE-mirror, an e-questionnaire that covered a specific set of entrepreneurial competencies. After completing the questionnaire and printing out a 'development report' on the results, the participant together with an advisor walked through all the answers that were chosen. Based on this conversation, the advisor decided whether the participant was a candidate for the entrepreneurial training programmes offered by the partners of the ENTRE project. The report produced by the ENTRE-mirror was subsequently used in the training programmes to create a functional development plan that recorded the participant's chosen aim and learning process. This led to an individualised learning trajectory in which the participant worked on authentic and complex tasks. For all these individualised training sessions, experiments were set up to evaluate the results. These were used to redesign the programmes and train the trainers to better fulfil their role not only as instructors, but also as learning facilitators and coaches.

\section{Case study results}


In this section the results of the case study are explored in relation to the broadly defined research questions presented in the introduction.

How was the concept of entrepreneurial competence operationalised?

Both training programmes adopted an integrated model of competence, emphasising the improvability of entrepreneurial competence as well as its integrated character. Competencies were defined in both cases as the integration of knowledge, skills and attitudes. Competencies were not regarded as static personal characteristics, but viewed as learnable, provided that intellectual capacities and a necessary motivational basis are present. In both cases a generic framework of competencies for small- and medium-sized enterprises presented by Man et al. (2002) was used as the point of departure. Competencies in this conceptualisation are generic, however they can be made concrete by considering the content or context of the specific profession. In the RI case this framework of generic competence clusters (opportunity, relationship, conceptual, strategic, organising and commitment) was translated into 21 underlying competencies and indicators for the agri-food sector by means of a literature study and a multi-rater assessment with entrepreneurs, experts and peers (professional colleagues) ( $\mathrm{n}=16)$ (see Lans et al., 2005). In the ENTRE project, the initial framework of Man et al. (2002) was expanded by means of a literature study and a group discussion with entrepreneurs and experts in entrepreneurship education, which resulted in the addition of an extra cluster of competencies, namely social responsibility. Accordingly, these seven clusters were further refined to 12 underlying competencies based on an exploratory factor analysis ( $\mathrm{n}=1222)$ (see Baert and Camertyn, 2007).

What principles and methods were used to diagnose entrepreneurial competencies?

In both cases a self-assessment instrument was designed to diagnose individual entrepreneurial competencies and consequent potential learning needs. The starting point for the self-assessment was an e-questionnaire, in which the respondents had to rate statements that corresponded (positively or negatively) to the identified set of entrepreneurial competencies. In the Dutch RI case, the small farm holders each received a report on their scores, with a 'translation' of the results to their specific sector. For each of the discerned competence clusters a detailed description was given of how these competencies were 
stipulated and what the importance of these competencies were for pluriactivity in agriculture. Furthermore the participants received a comparison of their individual scores with those of the group as a whole and the results were discussed in the group. The facilitator of each group was provided with an overview of the scores of all the participants and given the assignment to discuss the results. Different strategies were followed by the facilitators to address the results of the e-questionnaire. One strategy was to focus on specific critical situations in working life (critical incidents) which were related to a concrete business idea that a group wanted to explore. The objective of this strategy was mainly to confront small business owners with concrete settings, their own behaviour in those settings, and possible areas for improvement. A second strategy was to invite owners who scored high on a specific competence to discuss why they thought they were competent in that area. A third strategy that was employed could be labelled as using competence from a learning needs perspective. The participants were asked to sketch their ambitions for business, and subsequently translate these developments into their own individual requirements for achieving these projections. For example, if the owners in a group wanted to expand their businesses in the direction of establishing a care farm, the discussion focussed on the use and importance of relational competencies in this context.

In the Flemish case, a self-assessment instrument referred to as the ENTRE-mirror was developed. Like in the RI case, this instrument contained statements that corresponded negatively/positively to certain competencies. The instrument was further equipped with short instructional information, some introductory questions and a topic list for interpretation and reflection. This instrument had been pre-tested with 60 aspirant entrepreneurs and unemployed individuals who were motivated to follow an entrepreneurship course. The term mirror was used to emphasise that the instrument was not a test or a screening of objective characteristics, but a self-help tool: it invites the participant to learn about him- or herself, gives meaning to the results of the assignment and their implications for entrepreneurship and encourages the participant to engage in initial or follow-up learning (by providing a list of websites on the development of entrepreneurship). After completing the questionnaire and printing out the 'development report', the participant together with an advisor walked through all the answers that were chosen. The participant's answers were then compared with norm scores (minimum and maximum scores) and the aggregated score per competence (norm scores were calculated by asking 113 successful small business owners to reflect on their experiences and indicate which of the identified competencies they considered to be 
essential to start up a new business or take over a business in its first three years). The discussion after completing the questionnaire was intended to shed more light on whether the participant really understood the questions and how accurate his or her self-assessment was. Based on this information, the advisor decided whether or not the participant was a candidate for the entrepreneurial programmes offered by the partners of the ENTRE project: SYNTRA Vlaanderen (Flemish Agency for Entrepreneurial Training), UNIZO (Union of selfemployed entrepreneurs) and VDAB (Flemish Employment and Vocational Training Agency). Concretely, at the time of the ENTRE-project, this involved the following training programmes: business management, manager, hotel management, estate agent, commercial representative and baker. The leading principle in this case was to create a functional development plan for the participant, which would lead to an individualised learning trajectory and the creation of a more powerful learning environment. This learning environment would consist of authentic and complex tasks (such as case studies, simulations, mini projects) in addition to instruction, but also of individual discussions, self reflection, learning action in the class and feedback exercises. In this way, the training was conceived as an opportunity to exercise all of the participants' competencies that would apply in his or her future work situation.

What were the experiences of participants with competence-based instruments for learning trajectories aimed at entrepreneurship?

What was poignant in both cases was the lack of clarity regarding how entrepreneurial competence relates to performance in general. There was confusion about what was actually being measured in the competence-focussed self-assessment (e.g. personality versus competence). Misunderstandings about the self-assessment instrument led in the Flemish case to a description not only of what the self-assessment was, but also of what it was not. For instance, scores produced by the self-assessment would not provide participants with an answer to the question 'Am I, at present, competent (or not) to be a successful entrepreneur?', nor would they say anything about the likelihood for success if a candidate were to start a business right away. Similar misunderstandings occurred in the RI case. The 'learned competence' perspective was not communicated clearly from the beginning to the participants, which led to confusion and sometimes irritation among the small business owners. The participants indicated for instance that some specific personality traits for 
successful entrepreneurship (e.g. risk-taking, need for achievement) were missing. Furthermore, since competence descriptions were framed from specific entrepreneurial tasks and activities, the owners did not always recognise themselves directly in the questions, which in some cases led to irritation.

The added value of working with competencies lies primarily in creating awareness of one's own entrepreneurial competence profile (e.g. strengths and weaknesses) and providing focus regarding the directions for development. In the Dutch case, for example, $85 \%$ of the participants indicated that the training contributed to insight into their own entrepreneurial competencies. About $85 \%$ indicated that the training helped them strengthening their competencies, 75\% claimed that it also helped them developing new (aspects) of entrepreneurial competence, such as developing a critical attitude towards their product and company, expanding their horizons, inspiring colleagues, developing a market plan and making a useful inventory of their networks. However, creating awareness requires more than just completing an e-questionnaire. Follow-up activities are necessary to sharpen the results of the intake. In the Flemish case the conclusion the e-questionnaire generated did not automatically match the advisor's conclusion and final decision. Both cases indicated that a reflection meeting after completion of the questionnaire is an indispensable part of the assessment because it sheds more light on whether the participant really understood the questions, whether he or she over- or underestimated him- or herself and whether the answers match any other personal data about the participant possessed by the facilitator or advisor.

Although the competencies in both cases were formulated from a learning perspective, the translation of individual competence into individual learning activities appeared to be a complex task and is not something that happens automatically. The experience in the RI project taught us that personal development should be connected to business development models based on concrete, authentic and complex situations. Experience in the Flemish case taught us that the competence-developing approach works best in a group of no more than 20 participants led by a very limited number of trainers. It also works best if applied in a linear learning trajectory involving the same group of learners rather than in a modular, discontinuous structure. In both cases the facilitator played a key role in translating the competence requirements to concrete learning activities. For instance, in the RI project, participants practiced certain competencies, like negotiating skills or perseverance, via role playing, e.g. negotiating with a potential investor or presenting a 
concrete business plan to the bank. In the Flemish case complex tasks were used, such as case studies, simulations and mini projects.

\section{Discussion}

From a theoretical point of view, the concept of competence is assumed to be relevant, learnable, assessable and closely related to performance. Nevertheless, in practice the concept is often poorly defined and ambiguous. In this paper we argued that modern conceptualisations of entrepreneurial competence can be powerful constructs to connect and stimulate use of multiple dimensions of entrepreneurship in entrepreneurship education. Although this study does not give an answer to the question of whether competence-based entrepreneurship training is more successful in developing entrepreneurship than 'traditional' entrepreneurship training, we were able to touch upon important experiences in the use of a competence-based approach in two settings. Both of the cases illustrate that a competence-based approach, which departs from an integrative and interpretive perspective, is of added value for entrepreneurship training.

Concerning our central research questions, the results of the cases show that the nature of entrepreneurial competence should be a point of discussion already before the start of a programme. For instance the identification of crucial competencies could be an important learning activity for teachers/coaches/mentors, entrepreneurs and others involved. This activity would trigger all stakeholders to critically think about which competencies are necessary, desirable and learnable in a specific context. It would specifically help teachers, consultants or facilitators to engage in entrepreneurial practice. In their study on the implementation of competence-based education, Wesselink et al. (2007) stated that competencies, which are the basis for learning trajectories, should be formulated with care and in close dialogue with relevant business partners and colleagues.

Creating a dialogue by discussing and interpreting entrepreneurial competence seems to be key in translating self-assessment scores into individual directions for competence development. It is fundamental that competence is treated as an item for discussion and interpretation rather than as a fixed template of boxes to be ticked. What kinds of experiences constitute the core of entrepreneurial competence, how they were acquired, which experiences were most influential, and so on. Moreover, discussing the concept of entrepreneurial competence can 'personalise' it in several ways. First of all, it can link entrepreneurial competence to entrepreneurial identity (Rae, 2006), i.e. 'What do I want, 
aspire to, as an entrepreneur', thereby connecting a competence assessment to important entrepreneurial drivers now and in the future. Secondly, discussion can lead to a more realistic self-image ('What is it that I am really good at'?), which is an important condition for (future) performance (Fletcher and Bailey, 2003). In the context of entrepreneurship education, the importance of this dialogue implies that care must be taken in guiding potential training participants through the intake process.

The next step of translating the concept into viable learning activities is not easy. The added value of using competence identification and assessment instruments is that they provide focus regarding the direction competence development should take. In other words, they point the way, but do not dictate how to get there. Further contextual deliberation is needed to choose the learning activities that will most effectively contribute to achieving business success. The notion of 'entrepreneurial core problems/challenges' is important here (e.g. the 'breakthrough agenda' in the Dutch case and the complex tasks in the Flemish case). What these cases make clear is that this approach demands a great deal from the teachers involved (e.g. they must serve as coaches, facilitators and/or mentors). Thus, in the studied cases, the success of the use of competencies in the learning process depended to a large extent on the individual capacity of the facilitator to translate self-assessment results into meaningful starting points for the participant's personal development.

\section{Conclusion and recommendations}

One of the central elements in this paper was the notion that adopting a competence-based framework in entrepreneurship education might connect and stimulate use of different dimensions of entrepreneurship in entrepreneurship education and training. In this paper we tried to shed more light on the concept of entrepreneurial competence as a powerful construct to realise this from a theoretical as well as practical point of view.

Concerning the future direction of entrepreneurship education research on the concept of competence, one interesting issue is the level of analysis of entrepreneurial competence. Entrepreneurial competencies do not necessarily have to be limited to one single person in a (future) business. Competencies can for instance be distributed among management or start-up teams. Conceptual questions to be addressed include: What is the relation between individual competence and collective competence? Is complementarily enough or is there a minimum level of competence for each individual required? In general, the increased importance of entrepreneurial teams in business and between businesses raises 
several interesting future research questions concerning distributed competencies and the role this plays in pursuit of entrepreneurial opportunities.

Finally, although assessment is an important part of entrepreneurship education and training, it remains difficult to recapitulate when competence development has actually taken place. In both of the cases studied, the projects had not yet reached the phase to really capture competence development. However, we think that it is important to discuss it, since learning and development were aims of both projects. Models of professional development in professions such as teaching and nursing have typically been described in stages or phases, based for instance on dominant areas of interest and problems. Novices start with limited professional knowledge, develop themselves further to advanced beginner and eventually to expert level (Dreyfus and Dreyfus, 1986). These models of development describe change on two levels, namely i) moving from the use of abstract principles towards the use of concrete experiences as a frame of reference in situations (i.e. broadening of competence) and ii) change in perception and understanding of demanding situations (i.e. deepening of competence). However, research on learning and work has questioned the wisdom of stage models in professional development (Dall'Alba and Sandberg, 2006). It challenges the problematic assumption that development is always positive; the strong association it has with accumulation, increase, growth and build up of knowledge and skills; and the lack of attention it gives to the role of reflection and the work environment in fostering it. Therefore, alternative models of competence development are suggested (e.g. Dall'Alba and Sandberg, 2006). In future research it might be interesting to explore the value of these different models in entrepreneurial learning settings.

\section{Acknowledgements}

The authors would like to thank all the participants (aspirant entrepreneurs, small business owners, consultants, facilitators and researchers) in the ENTRE and PlattelandImpuls projects for sharing their thoughts, ideas and critical insights.

\section{References}

Baert, H. and Camertijn, C. (2007). Zelfbeoordeling van ondernemerscompetenties in een competentiegericht ontwikkelingstraject: de ENTRE-spiegel. Onderwijs Research Dagen 2007, Groningen.

Baert, H., De Witte, K., and Sterck, G. (2000). Vorming, training en opleiding. Handboek voor een kwaliteitsvol VTO-beleid in welzijnsvoorzieningen. Garant, Leuven. 
Bandura, A. (1982). Self-efficacy Mechanism in Human Agency. American Psychologist, 37(2): 122-147.

Baron, R.A. and Ensly, M.D. (2006). Opportunity Recognition as the Detection of Meaningful Patterns: Evidence from Comparisons of Novice and Experienced Entrepreneurs. Management Science, 52(9): 1331-1344.

Bolden, R. and Gosling, J. (2006). Leadership Competencies: Time to Change the Tune? Leadership 2(2): 147-163.

Baum, R.J. and Locke, E.A. (2004). The Relationship of Entrepreneurial Traits, Skill, and Motivation to Subsequent Venture Growth. Journal of Applied Psychology, 89(4): 587598.

Biemans, H., Nieuwenhuis, L., Poell, R., Mulder, M. and Wesselink, R. (2004). Competence-based VET in the Netherlands: Background and Pitfalls. Journal of Vocational Education and Training, 56(4): 523-538.

Bird, B. (1995). Toward a theory of entrepreneurial competency, Advances in Entrepreneurship Firm Emergence and Growth, Greenwich, CT: JAI., pp. 52-72.

Boreham, N. (2006). The Co-construction of Individual and Organizational Competence in Learning Organizations, European Conference on Educational Research, Geneva, September 2006.

Boyatzis, R.E. (1982). The Competent Manager. John Wiley \& Sons, New York.

Carter, S. (2001). Multiple Business Ownership in the Farm Sector: Differentiating Monoactive, Diversified and Portfolio Enterprises. International Journal of Entrepreneurial Behaviour \& Research, 7(2): 43-59.

Cheetham, G. and Chivers, G. (1996). Towards a Holistic Model of Professional Competence. Journal of European Industrial Training, 20(5): 20-30.

Collins, L.A., Smith, A.J. and Hannon, P.D. (2006). Discovering Entrepreneurship - an Exploration of a Tripartite Approach to Developing Entrepreneurial Capacities. Journal of European Industrial Training, 30(3): 188-205.

Cope, J. and Watts, G. (2000). Learning by Doing: an Exploration of Experience, Critical incidents and Reflection in Entrepreneurial Learning. International Journal of Entrepreneurial Behaviour and Research 6(3): 104-124.

Dall'Alba, G. and Sandberg, J. (2006). Unveiling Professional Development: a Critical Review of Stage Models. Review of Educational Research, 76(3): 383-412.

Defillippi, R.J. and Arthur, M.B. (1994). The Boundaryless Career: a Competency-based Perspective. Journal of Organizational Behavior, 15: 307-324.

Delamare Le Deist, F. and Winterton, J. (2005). What is Competence? Human Resource Development International, 8(1): 27-46.

Delmar, F. and Goujet, R. (2006). How do you React to Entrepreneurship Education? An 
Examination of the role of Predispositions in an Enactive Mastery Experience of

Entrepreneurship. Paper presented at the RENT XX Conference, Brussels, Belgium, November 23-24.

Dreyfus, H.L. and Dreyfus, S.E. (1986). Mind over Machine: the Power of Human intuition and Expertise in the Era of the Computer. New York: Free Press.

Eraut, M., (1994). Developing Professional Knowledge and Competence. The Falmer Press, London. Fayolle, A. and Klandt, H. (2006). International Entrepreneurship Education - Issues and Newness. Edward Elgar, Cheltenham, UK.

Fiet, J.O. (2001). The Pedagogical Side of Entrepreneurship Theory. Journal of Business Venturing 16(2): 101-117.

Fletcher, C. and Bailey, C. (2003). Assessing Self-awareness: Some Issues and Methods. Journal of Managerial Psychology, 18(5): 395-404.

Fuller-Love, N. (2006). Management Development in Smaller Firms. International Journal of Management Reviews, 8(3): 175-190.

Gibb, A. (2002). Creating Conducive Environments for Learning and Entrepreneurship: Living with, Dealing with, Creating and Enjoying Uncertainty and Complexity. Industry and Higher Education, 16(3): 134-148.

Hayton, J.C. and Kelley, D.J. (2006). A Competency-based Framework for Promoting Corporate Entrepreneurship. Human Resource Management, 45(3): 407-427.

Honig, B. (2004). Entrepreneurship Education: Toward a Model of Contingency-based Business Planning. Academy of Management Learning and Education, 3(3): 258-273.

Katz, J. (2007). Education and Training in Entrepreneurship in J.R. Baum, M. Frese and R. Baron (eds). The Psychology of Entrepreneurship, SIOP organisational Frontier Series, Lawrence Erlbaum, New Jersey.

Lans, T., Bergevoet, R., Mulder, M. and Van Woerkum, C. (2005). Identification and Measurement of Competences of Entrepreneurs in Agribusiness in Batterink, M., R. Cijsouw, M. Ehrenhard, H. Moonen and P. Terlouw (eds). Selected papers from the 8th Ph.D. Conference on Business Economics, Management and Organization Science, PREBEM/NOBEM, Enschede.

Man, T.W.Y. (2006). Exploring the Behavioural Patterns of Entrepreneurial Learning: a Competency Approach. Education + Training, 48(5): 309-321.

Man, T. W. Y., Lau, T. and Chan, K. F. (2002). The Competitiveness of Small and Medium Enterprises - A Conceptualization with Focus on Entrepreneurial Competences. Journal of Business Venturing, 17: 123-142.

Mansfield, B. (2003). Competence in Transition. Journal of European Industrial Training, 28: 296309. 
Markman, G.D. (2007). Entrepreneurs’ Competencies in J.R. Baum, M. Frese and R. Baron (eds.). The Psychology of Entrepreneurship, SIOP organisational Frontier Series, Lawrence Erlbaum, New Jersey.

Markman, G.D. and Baron, R.A. (2003). Person-entrepreneurship Fit: Why Some People are More Successful as Entrepreneurs than Others. Human Resource Management Review, 13: 281301.

Maurer, T.J., Wrenn, K.A., Pierce, H.R., Tross, S.A. \& Collins, W.C. (2003). Beliefs About 'Improvability’ of Career-relevant Skills: Relevance to Job/task Analysis, Competency Modelling, and Learning Orientation. Journal of Organizational Behavior, 24: 107-131.

McClelland, D.C. (1973). Testing for Competence Rather than Intelligence. American Psychologist 28: $1-14$.

McClelland, D.C. (1987). Characteristics of Successful Entrepreneurs. The Journal of Creative Behaviour, 21(3): 219-233.

McClelland, D.C. (1998). Identifying Competences with Behavioural-event Interviews. Psychological Science, 9(5): 331-339.

Mulder, M. (2001). Competence Development - Some Background Thoughts. The Journal of Agricultural Education and Extension, 7(4): 147-158.

Mulder, M., Lans, T., Verstegen, J., Biemans, H. and Meijer, Y. (2007). Competence Development of Entrepreneurs in Innovative Horticulture. Journal of Workplace Learning, 19(1): 32-44.

Rae, D. (2006). Entrepreneurial Learning: a Conceptual Framework for Technology-based Enterprise. Technology Analysis \& Strategic Management, 18(1): 39-56.

Rauch, A. and Frese, M. (2007). Born to Be an Entrepreneur? Revisiting the Personality Approach to Entrepreneurship in J.R. Baum, M. Frese and R. Baron (eds). The Psychology of Entrepreneurship, SIOP organisational Frontier Series, Lawrence Erlbaum, New Jersey.

Rothwell, W.J. and Lindholm, J.E. (1999). Competency Identification, Modelling and Assessment in the USA. International Journal of Training and Development, 3(2): 90-105.

Sandberg, J. (2000). Understanding Human Competence at Work: An Interpretative Approach. The Academy of Management Journal, 43(1): 9-25.

Schoorlemmer, H. and Wolf, P. de (2008). Een impuls voor plattelandsondernemers: methodiekbeschrijving en evaluatie van Plattelandimpuls. Praktijkonderzoek Plant en Omgeving, Lelystad.

Stevenson, H.H. and Gumpert, D.E. (1985). The Heart of Entrepreneurship. Harvard Business Review, March-April, 1-11.

Stoof, A., Martens, R. L., Van Merriënboer, J. J. G., and Bastiaens, T. J. (2002). The Boundary Approach of Competence: A Constructivist Aid for Understanding and Using the Concept of Competence. Human Resource Development Review, 1: 345-365. 
Sullivan, R. (2000). Entrepreneurial Learning and Mentoring. International Journal of Entrepreneurial Behaviour and Research, 6(3): 160-175.

Van der Klink, M.R. and Boon, J. (2003). Competencies: The Triumph of a Fuzzy Concept.

International Journal of Human Resources Development and Management, 3(2): 125-137.

Wesselink, R., Biemans, H.J.A., Mulder, M. and van den Elsen, E.R. (2007). Competence-based VET as seen by Dutch researchers. European Journal of Vocational Training, 40: 38-51. 


\section{Publications in the ERIM Report Series Research* in Management}

\section{ERIM Research Program: "Organizing for Performance"}

\section{8}

Explaining Preferences and Actual Involvement in Self-Employment: New Insights into the Role of Gender Ingrid Verheul, Roy Thurik and Isabel Grilo ERS-2008-003-ORG

http://hdl.handle.net/1765/10979

Public Finance in China since the Late Qing Dynasty

Barbara Krug

ERS-2008-005-ORG

http://hdl.handle.net/1765/11287

Overoptimism among Founders: The Role of Information and Motivation

Ingrid Verheul and Martin Carree

ERS-2008-008-ORG

http://hdl.handle.net/1765/11557

Do Foreign Greenfields Outperform Foreign Acquisitions or Vice Versa? An Institutional Perspective

Arjen H.L. Slangen and Jean-François Hennart

ERS-2008-009-ORG

http://hdl.handle.net/1765/11558

Unemployment Benefits Crowd Out Nascent Entrepreneurial Activity

Philipp Koellinger and Maria Minniti

ERS-2008-012-ORG

http://hdl.handle.net/1765/11808

Acceleration of Technology Adoption within Firms: Empirical Evidence from the Diffusion of E-business Technologies Philipp Koellinger and Christian Schade

ERS-2008-013-ORG

http://hdl.handle.net/1765/11809

Belbin Revisited: The Construct Validity of the Interplace II Team Role Instrument

Dirk van Dierendonck and Rob Groen

ERS-2008-017-ORG

http://hdl.handle.net/1765/12123

China's Institutional Architecture: A New Institutional Economics and Organization Theory Perspective on the Links between Local Governance and Local Enterprises

Barbara Krug and Hans Hendrischke

ERS-2008-018-ORG

http://hdl.handle.net/1765/12191

Ethics Programs and Ethical Cultures: A Next Step in Unraveling their Multi-Faceted Relationship

Muel Kaptein

ERS-2008-020-ORG

http://hdl.handle.net/1765/12192

Entrepreneurship Education and Training in a Small Business Context: Insights from the Competence-based Approach Thomas Lans, Wim Hulsink, Herman Baert and Martin Mulder

ERS-2008-028-ORG

http://hdl.handle.net/1765/12466 
The Relationship between Technology, Innovation, and Firm Performance: Empirical Evidence on E-Business in Europe Philipp Koellinger

ERS-2008-031-ORG

http://hdl.handle.net/1765/12469

* A complete overview of the ERIM Report Series Research in Management: https://ep.eur.nl/handle/1765/1

ERIM Research Programs:

LIS Business Processes, Logistics and Information Systems

ORG Organizing for Performance

MKT Marketing

F\&A Finance and Accounting

STR Strategy and Entrepreneurship 